\title{
KAJIAN UTILITAS KENDARAAN ANGKUTAN KOTA YANG BERNILAI ERGONOMI DENGAN PENDEKATAN ANTROPOMETRI
}

\author{
Ahmad Hanafie ${ }^{1}$, Hammada Abbas ${ }^{2}$, Lawalenna Samang ${ }^{3}$ dan Sumarni Hamid ${ }^{4}$ \\ ${ }^{1}$ Mahasiswa Program Doktor Teknik Sipil, Universitas Hasanuddin \\ Jalan Perintis Kemerdekaan KM-10, Telp 081355769788, Email: ahmadhanafie@yahoo.co.id. \\ ${ }^{2}$ Dosen Jurusan Teknik Mesin, Universitas Hasanuddin \\ Jl.Perintis Kemerdekaan,Km.10,Telp085340570417,Email: hammadaabbas@yahoo.co.id \\ ${ }^{3}$ Dosen Jurusan Teknik Sipil, Universitas Hasanuddin \\ Jalan Perintis Kemerdekaan KM-10, Telp 0411-587636., Email: samang_l@yahoo.com \\ ${ }^{4}$ Dosen Jurusan Teknik Sipil, Universitas Hasanuddin \\ Jalan Perintis Kemerdekaan KM-10, Telp 0411-587636,Email: marni_hamidaly@yahoo.com
}

\begin{abstract}
Teknologi yang dikembangkan selama ini adalah untuk memenuhi kebutuhan manusia, maka semestinya manusia harus dimanjakan. Tetapi jika ternyata semua itu tidak membuat manusia merasa aman, nyaman, sehat dan mudah, maka berarti dalam proses perancangan, pengambilan keputusan dan pembangunannya telah mengalami penyimpangan orientasi. Sarana transportasi Angkutan Umum di Kota Makassar mestinya dibuat dengan memperhatikan aspek ergonomis, namun tidak demikian halnya dengan sarana transportasi untuk umum. Masalah mengenai kendaraan umum meliputi akses turun naik, hangar, tata kursi kurang sesuai dengan pengguna kendaraan. Tujuan penelitian adalah untuk mengkaji utilitas kendaraan umum yang bernilai ergonomis dengan pendekatan antropometri., untuk menganalisis bagian-bagian tubuh yang tidak sesuai dengan utilitas kendaraan. Metode pengumpulan data yang dilakukan adalah pengukuran dimensi tubuh pada penumpang lalu dianalisis dengan pendekatan antropometri yang ergonomi. Berdasar hasil penelitian ukuran utilitas kendaraan umum yang bernilai ergonomi dengan pendekatan antropometri untuk bagian hangar diperoleh ukuran 104,78 cm, ukuran tinggi tangga pertama $23,75 \mathrm{~cm}$, dan lebar tangga $24,25 \mathrm{~cm}$, Ukuran lebar kursi/bangku $36,21 \mathrm{~cm}$, ukuran tinggi kursi $44,45 \mathrm{~cm}$ dan ukuran tinggi sandaran $29,84 \mathrm{~cm}$. Tinggi hangar disesuaikan dengan tinggi siku berdiri sehingga pengguna lebih fleksibel untuk menjangkau hangga, tinggi tangga pertama disesuai dengan tinggi lutut diambil $1 / 2$ tinggi lutut untuk memudahkah penguna pada saat melangkah ketangga, kemudian lebar tangga disesuaikan dengan panjang telapak kaki, sedangkan untuk tata kursi lebar kursi/bangku disesuikan dengan pantat keperut supaya bila kita duduk merasakan kenyamanan dan tinggi kursi disesuikan dengan tinggi popliteal ke lantai, dan tinggi sandaran disesuikan bagian belakang tubuh agar tubuh bagian belakang tidak terbentur dengan benda keras.
\end{abstract}

Kata Kunci: Anthropometri, Ergonomi.

\section{PENDAHULUAN}

\subsection{Latar Belakang}

Di dalam proses produksi, sebelum perusahaan mengambil suatu keputusan untuk memproduksi suatu produk, terlebih dahulu dilakukan perencanaan produksi. Dimana perencanaan dilakukan agar bisa diketahui

Sarana transportasi Angkutan Umum di Kota Makassar mestinya dibuat dengan memperhatikan aspek ergonomis, namun 
tidak demikian halnya dengan sarana transportasi untuk umum. Penghargaan terhadap nilai kemanusiaan secara umum nampaknya masih dinomorduakan setelah tujuan ekonomis. Sehingga dalam banyak hal masih banyak ditemukan nilai kemanusiaan tidak dijadikan acuan penting dalam proses rancang bangun.

Permasalahan yang ada dalam penelitian ini adalah mengenai kendaraan umum yang ada di kota Makassar. Masalah pertama utilitas kendaraan umum dari 140 kendaraan yang diteliti tidak mempunyai kesamaan tentang ukuran bahkan ada sebagaian kendaraan tidak mempunyai fasilitas yang mestinya ada pada kendaraan angkutan umum, meliputi akses turun naik seperti tangga pertama tinggi $32-48 \mathrm{~cm}$, tangga kedua tingginya $52-73 \mathrm{~cm}$, lebar pintu masuk $65-72 \mathrm{~cm}$ dan lebar tangga pertama sebagai injakan kaki $16-24 \mathrm{~cm}$. Hanggar adalah sebagai tempat pegangan tangan pada saat penumpang akan naik di kendaraan, jarak hangar dengan jalanan berkisar $100-205 \mathrm{~cm}$. Tata kursi yang meliputi tinggi kursi $25-35 \mathrm{~cm}$, panjang kursi pertama $185-233 \mathrm{~cm}$, panjang kursi kedua 120 - $160 \mathrm{~cm}$, tinggi sandaran 20 -36 $\mathrm{cm}$.

Dari ukuran akses naik tentunya penunpang mengalami kesulitan jarak antara dasar jalanan dengan tangga cukup tinggi sehingga penumpang yang mempunyai postur tubuh yang lebih kecil dan perempuan yang mengunakan rok akan mengalami kesulitan ini disebabkan keterbatasan kemampuan manusia, hangar pintu diukur dari lantai yang tidak sesuai dengan jangkauan tangan bagi pengguna kendaraan tidak sama, tinggi kursi penumpang yang tidak dirancang sesuai dengan kondisi tubuh penumpang sehingga pengguna jika mereka duduk cepat merasakan sakit pada bagian tubuh yang tentunya penguna kendaraan umum akan mengalami kurang nyaman dalam berkendara.

Dalam Kajian penelitian yang ingin dicapai adalah utilitas kendaraan umum kendaraan angkutan umum menjadi aman dan nyaman yang bernilai egonomi dengan pendekatan antropometri.

\subsection{Perumusan Masalah}

Berdasarkan uraian tersebut diatas masalah dalam penelitian ini dapat dirumuskan: 1. Mengkaji utilitas kendaraan umum yang bernilai ergonomis dengan pendekatan antropometri., 2. Menganalisis bagian-bagian tubuh yang tidak sesuai dengan utilitas kendaraan,

\subsection{Tujuan Penelitian}

sedangkan dari rumusan masalah maka, maka tujuan penelitian 1. Untuk mengkaji utilitas kendaraan umum yang bernilai ergonomis dengan pendekatan antropometri., 2. Untuk menganalisis bagian-bagian tubuh yang tidak sesuai dengan utilitas kendaraan.

\subsection{Manfaat Penelitian}

Adapun kegunaan penelitian dapat bermanfaat bagi:

\section{- Masyarakat Pengguna}

Bagi Masyarakat pengguna, dapat memberikan pelayanan yang baik pada pengguna angkutan umum yang ada di Kota Makassar, sehingga masyarakat pengguna merasa kenyaman dan aman.

\section{- Akademi}

Bagi perguruan tinggi, hasil penelitian diharapkan dapat menjadi dokumen akademik yang berguna untuk dijadikan acuan bagi civitas akademika.

\section{- Mahasiswa}

Bagi mahasiswa, seluruh rangkaian kegiatan dan hasil penelitian diharapkan dapat lebih memantapkan penguasaan fungsi keilmuan yang dipelajari selama mengikuti program pascasarjana perkuliahan Ilmu Teknik Sipil pada Universitas Hasanuddin.

\section{METODOLOGI PENELITIAN}

\subsection{Tempat Penelitian}

Penelitian dilakukan di Kota Makassar, pemilihan Kota Makassar dengan pertimbangan bahwa Kota tersebut mempunyai pengguna anggkutan yang cukup 
besar namun, dari segi utilitas kendaraan belum optimal pada kendaraan umum.

Populasi dan sampel penelitian adalah pengguna angkutan umum, pada utilitas kendaraan anak-anak sekolah, mahasiswa, Pegawai Negeri maupun Swasta dan penumpang umum.

\subsection{Rancangan Penelitian}

Rumusan masalah dalah penelitian adalah bagaimana tingkat ergonomis keamanan dan kenyamanan terhadap utilitas kendaraan umum. Secara terpadu.

Jenis dan sumber data yang diperlukan dalam penelitian ini:

- Data primer yaitu data yang diperoleh yaitu pertama, Observasi mengadakan penelitian atau pengamatan pada obyek penelitian berupa pengamatan langsung terhadap kendaraan umum. Kedua Interview melakukan wawancara kepada para pengguna angkutan umum.

- Data skunder yaitu data yang diperoleh dari buku dan penelitian-penelitian sebelumnya dari berbagai sumber bacaan yang berkaitan dengan penelitian.

Dalam penelitian dilakukan identifikasi variabel penelitian yang akan menjadi dasar dalam penentuan langkah-langkah penelitian selanjutnya variabel penelitian tersebut adalah jenis kenyamanan dan keamanan pengguna angkutan umum .

Pada penelitian ini, populasi yang menjadi obyek penelitian adalah penggunan angkutan umum yaitu pegawai, anak sekolah, mahasiswa dan penumpang umum lainnya. Adapun sampel yang akan diambil sekitar 140 sampel, dengan proporsi jumlah kuesioner yang dianggap benar $95 \%$ dan proporsi jumlah kuesioner yang dianggap salah adalah $5 \%$, maka jumlah sampel mínimum yang akan digunakan.

Pengumpulan data kualitatif dilakukan untuk mengetahui apa keinginan penggunan angkutan umum di kota Makassar dengan cara yang dilakukan penyebaran kuesioner terhadap penggunaka angkutan umum dengan berbagai pertanyaan/butir.
Pengumpulan data dilakukam secara langsung pada kenyamanan dan keamanan pada kendaraan umum terutama pada bagian akses naik turun, hangar, tata letak kursi.

Setelah data diperoleh lalu dilanjutkan dengan pengujian statistik

- Dalam uji keseragaman data dikatakan seragam bila mana data berada diantara Batas Kontrol Atas dan Batas Kontrol Bawah dengan menggunakan tingkat kepercayaan $95 \%$ dan tingkat ketelitian $5 \%$.

- Uji Kecukupan data, gunanya untuk mengetahui data cukup atau tidak dengan syarat $\mathrm{N}^{\prime}<\mathrm{N}$, dengan tingkat kepercayaan $95 \%$ dan tingkat ketelitian $5 \%$.

- Uji Persentil, dengan $\mathrm{P}(5), \mathrm{P}(50)$ dam $\mathrm{P}$ (95)

\subsection{Metode Analisis}

Dalam penelitian ini, populasi yang menjadi obyek penelitian, untuk menentukan jumlah sampel penelitian digunakan peesamaan bernoulli yaitu:

$$
N \geq \frac{\left(z_{\alpha / 2}\right)^{2} \mathbf{p} \cdot \mathbf{q}}{e^{2}}
$$

Setelah dilakukan pengambilan data kendaraan lalu dilanjutkan dengan pengukuran dimensi tubuh pengguna kendaraa, kemudian dilakukan analisis uji keseragaman data yaitu Batas kontrol atas (BKA) dan Batas kontrol bawah (BKB).

$$
\begin{aligned}
& B K A=\bar{X}+2 \sigma_{x} \\
& B K B=\bar{X}-2 \sigma_{x}
\end{aligned}
$$

Dengan menggunakan tingkat kepercayaan $95 \%$ dan tingkat ketelitian $5 \%$. Hal Dari data dimensi tubuh yang diukur untuk tiap dimensi akan memiliki penyimpanan tidak lebih dari $5 \%$. Data dikatacukup apabila $\mathrm{N}^{\prime}<\mathrm{N}$, Dengan menggunakan rumus yaitu :

$N^{\prime}=\left[\frac{K / S \sqrt{N \sum X_{i}{ }^{2}-\left(\sum X_{i}\right)^{2}}}{\sum X_{i}}\right]^{2}$ 
Test Persentil dilakukan untuk menguji ukuran data yang digunakan pada obyek yang diteliti dengan rumus :

$P(5)=\bar{x}-1.65 \sigma x$

$P(95)=\bar{x}+1.65 \sigma x$

\section{ANALISA DAN PEMBAHASAN}

\subsection{Hasil Penelitian}

Ukuran kendaraan umum yang digunakan untuk mengangkut penumpang ketempat tujuan, ternyata utilitas kendaraan tidak ada ukuran yang sama dari 140 kendaraan yang diteliti dari 10 trayek yang ada dalam Kota Makassar dan 2 trayek Makassar- Maros dan Makassar- Pangkep diperoleh hasil sebagai berikut:

Tabel 3.1. Ukuran Utilitas Kendaraan Angkutan Umum

\begin{tabular}{clcc}
\hline No. & Utilitas Kendaraan & $\begin{array}{c}\text { Ukuran } \\
\text { Terendah } \\
(\mathrm{cm})\end{array}$ & $\begin{array}{c}\text { Ukuran } \\
\text { Tertinggi } \\
(\mathrm{cm})\end{array}$ \\
\hline $1 \quad$ Akses Naik Turun & & \\
& - Tangga Pertama & 32 & 48 \\
& - Tangga Kedua & 52 & 73 \\
& - Lebar Pintu & 65 & 72 \\
& - Lebar Tangga & 16 & 24 \\
2 & Hanggar & 100 & 205 \\
3 & Tata Kursi & & \\
& - Tinggi kursi & 25 & 35 \\
& - Panjang kursi & 185 & 233 \\
& pertama & & \\
$\quad$ - Panjang kursi & 120 & 160 \\
$\quad$ kedua & & \\
$\quad$ - Tinggi sandaran & 20 & 36 \\
\hline
\end{tabular}

Pengukuran dimensi tubuh penumpang pengguna angkutan umum sebanyak 150 responden, adapun dimensi diukur tiap responden sebanyak 48 dimensi tubuh. Berdasarkan hasil penelitian, maka dimensi tubuh yang berpengaruh terhadap utilitas kendaraan umum yaitu : Tinggi Lutut (1/2
TL), Siku ke Lantai (SL), Panjang Telapak Kaki (PTK), Tinggi Popliteal (TPL) diukur dari paha bagian bawah sampai di lantai, Tinggi Sandaran (TS), Pantat ke Perut (PP).

Pengujian keseragaman data sebagai alat kontrol dihitung rata-rata (mean), batas kontrol atas (BKA), batas kontrol bawah (BKB), dengan menggunakan tingkat kepercayaan $95 \%$ dan tingkat ketelitian $5 \%$. dapat dilihat pada tabel berikut.

Tabel 3.2. Hasil uji keseragaman antropometri

\begin{tabular}{ccccccc}
\hline No. & Dimensi & N & $\overline{\mathrm{X}}$ & BKA & BKB & Keterangan \\
\cline { 2 - 5 } 1 & SL & 150 & 101,22 & 105,55 & 96,90 & Seragam \\
2 & $1 / 2$ TL & 150 & 47,50 & 49,97 & 45,03 & Seragam \\
3 & PTK & 150 & 23,50 & 24,41 & 22,59 & Seragam \\
4 & PP & 150 & 31,59 & 37,21 & 25,97 & Seragam \\
5 & TPL & 150 & 41,06 & 45,18 & 36,94 & Seragam \\
6 & TS & 150 & 26,35 & 30,59 & 22,12 & Seragam \\
\hline
\end{tabular}

Dari hasil penguji keseragaman data diperoleh kelima dimensi tubuh yang diukur data berada diantara Batas Kontrol Atas (BKA) dan Batas Kontrol Bawah (BKB)yang artinya data seragama.

Dengan menggunakan tingkat kepercayaan $95 \%$ dan tingkat ketelitian $5 \%$. Dengan syarat kecukupan data N' $<$ N. Maka dapat dilihat pada tabel berikut.

Tabel 3.3. Hasil uji kecukupan antropometri

\begin{tabular}{ccccc}
\hline No. & Dimensi & N & N' & Keterangan \\
\cline { 2 - 3 } & Tubuh & & & \\
\hline 1 & SL & 150 & 10.92 & Cukup \\
2 & $1 / 2$ TL & 150 & 16,20 & Cukup \\
3 & PTK & 150 & 9,26 & Cukup \\
4 & PP & 150 & 13,64 & Cukup \\
5 & TPL & 150 & 59,96 & Cukup \\
6 & TS & 150 & 12,42 & Cukup \\
\hline
\end{tabular}

Dari hasil uji kecukupan data keenam dimensi tubuh dengan jumlah pengamatan 150 responden sedangkan N' berada di bawah 150 data yang artinya data sudah cukup. 
Tabel 3.4. Hasil uji persentil antropometri

\begin{tabular}{ccccc}
\multirow{2}{*}{ No. } & Dimensi & $5 \%$-ile & $50 \%$-ile & $95 \%$-ile \\
\cline { 2 - 5 } & Tubuh & $(\mathrm{cm})$ & $(\mathrm{cm})$ & $(\mathrm{cm})$ \\
\hline 1 & SL & 97,66 & 101,22 & 104,78 \\
2 & $1 / 2$ TL & 22,74 & 23,75 & 24,74 \\
3 & PTK & 22,75 & 23,75 & 24,25 \\
4 & PP & 26,97 & 31,59 & 36,21 \\
5 & TPL & 37,67 & 41,06 & 44,45 \\
6 & TS & 22,87 & 26,87 & 29,84 \\
\hline
\end{tabular}

Dari hasil uji persentil antropometri diperoleh sebagai acuan dalam perancangan utilitas kendaraan angkutan umum di Kota Makassar diperoleh hasil yaitu:

1. Ukuran untuk hangar, dimensi tubuh yang digunakan yaitu Siku ke lantai (SL)

- Persentil yang digunakan $95 \%=104,78$ $\mathrm{cm}$.

2. Ukuran untuk tinggi tangga pertama, dimensi tubuh yang digunakan $1 / 2$ Tinggi lutut $(1 / 2 \mathrm{TL})$

- Persentil yang digunakan $95 \%=23,75$ $\mathrm{cm}$

3. Ukuran untuk lebar tangga pertama, dimensi tubuh yang digunakan Panjang Telapak Kaki (PTK)

- Persentil yang digunakan $95 \%=24,25$ $\mathrm{cm}$

4. Ukuran untuk lebar kursi/bangku, dimensi tubuh yang digunakan diukur dari pantat ke perut (PP)

- Persentil yang digunakan $95 \%=36,21$ $\mathrm{cm}$

5. Ukuran untuk tinggi kursi/bangku, dimensi tubuh yang digunakan adalah Tinggi Popliteal ke Lantai (TPL)

- Persentil yang digunakan $95 \%=44,45$ $\mathrm{cm}$

6. Ukuran untuk tinggi sandaran, dimensi tubuh yang digunakan adalah Tinggi sandaran (TS)

- Persentil yang digunakan $95 \%=29,84$ $\mathrm{cm}$

\subsection{Pembahasan}

Dari hasil penelitian diperoleh ukuran utilitas kendaraan umum yang bernilai ergonomi dengan pendekatan antropometri untuk bagian hangar diperoleh ukuran 104,78 cm yang artinya pengguna angkutan umum sudah dapat menjangkau hangar sehingga dapat membantu pada saat naik ke kendaraan, ukuran tinggi tangga pertama $23,75 \mathrm{~cm}$, bisa digunakan semua penumpang dan lebar tangga $24,25 \mathrm{~cm}$ yang disesuaikan dengan panjang telapak kaki sehingga pada saat naik dikendaraan tidak terpeleset lagi, Ukuran lebar kursi/bangku 36,21 $\mathrm{cm}$ dapat memudahkan penumpang pada bila duduk serta tinggi kursi $44,45 \mathrm{~cm}$ sehingga pada saat duduk lutut tidak terlipat lagi dan tinggi sandaran $29,84 \mathrm{~cm}$.

Tinggi hangar disesuaikan dengan tinggi siku berdiri sehingga pengguna lebih fleksibel untuk menjangkau hangga, tinggi tangga pertama disesuai dengan tinggi lutut diambil $1 / 2$ tinggi lutut untuk memudahkah penguna pada saat melangkah ketangga, kemudian lebar tangga disesuaikan dengan panjang telapak kaki, sedangkan untuk tata kursi lebar kursi/bangku disesuikan dengan pantat keperut supaya bila kita duduk merasakan kenyamanan dan tinggi kursi disesuikan dengan tinggi popliteal ke lantai, dan tinggi sandaran disesuikan bagian belakang tubuh agar tubuh bagian belakang tidak terbentur dengan benda keras.

Hasil penelitian ini adalah bagian dari judul desertasi "Kajian Utilitas Kendaraan Dan Tempat Pemberhentian Angkutan Kota Yang Bernilai Ergonomi"

\section{PENUTUP}

\subsection{Kesimpulan}

1. Ukuran utilitas kendaraan umum yang bernilai ergonomi dengan pendekatan antropometri untuk bagian hangar diperoleh ukuran $104,78 \mathrm{~cm}$, ukuran tinggi tangga pertama $23,75 \mathrm{~cm}$, dan lebar tangga $24,25 \mathrm{~cm}$, Ukuran lebar kursi/bangku 36,21 cm, ukuran tinggi kursi $44,45 \mathrm{~cm}$ dan ukuran tinggi sandaran $29,84 \mathrm{~cm}$.

2. Tinggi hangar disesuaikan dengan tinggi siku berdiri sehingga pengguna lebih fleksibel untuk menjangkau hangga, tinggi tangga pertama disesuai dengan tinggi lutut diambil $1 / 2$ tinggi lutut untuk 
memudahkah penguna pada saat melangkah ketangga, kemudian lebar tangga disesuaikan dengan panjang telapak kaki, sedangkan untuk tata kursi lebar kursi/bangku disesuikan dengan pantat keperut supaya bila kita duduk merasakan kenyamanan dan tinggi kursi disesuikan dengan tinggi popliteal ke lantai, dan tinggi sandaran disesuikan bagian belakang tubuh agar tubuh bagian belakang tidak terbentur dengan benda keras.

\subsection{Saran}

1. Dari hasil analisa, maka disarankan kepada pemilik kendaraan memperhatikan aspek antropometri yang ergonomis.

\section{DAFTAR PUSTAKA}

Adhi Muhtadi, dkk (2012) Evaluasi Pelayanan Bus dan MPU Kota Surabaya Untuk Menunjang Sistem Transportasi Berkelanjutan, Bandung, Prosiding Konferensi Nasional Pascasarjana Teknik Sipil (KNPTS), hal. Tr 51-56.

Ahmad Hanafie, Sritomo W, (2003), Evaluasi Ergonomis Dalam Perancangan Fasilitas Kerja Untuk Proses Perontok Padi (Thresher), Yogyakarta, Procceding PEI.

Ar Anuj Jaiswal, Dr. Ashutosh Sharman, (2012), Optimization of Public Transport Demand: A Case Study Of Bhopal, New Delhi, International Journal of Scientific and Research Publications, Volume 2, Issue 7, 1-15.

Brendan Finn, ETTS Ltd. (2011), Urban Bus Services in Developing Countries and Countries in Transition: A Framework for Regulatory and Instutional Developments, Sydney, Journal Of Public Transportation, Vol. 14, 89-107.

Dedi Sulistiyo Soegoto, (2010), Peningkatan Prasarana, Sarana, Sistem Operasi Pelayanan Jasa Angkutan Umum Bis Kota Damri Berdasarkan Ekspektasi dan Persepsi Penumpang, Majalah Ilmiah UNIKOM, Vol. 8, No. 2, Hal. 217-229
Gempur Santoso, (2013), Ergonomi Terapan, Surabaya, Pustaka publisher.

Geetam Tiwari, 2002, Urban Transport Priorities, Cities, Britain, Pergamon, Vol. 19,2. Pp. $95-103$.

Iftikar Z. S.; Ruhana A; John H. T (2010), Analisa dan Perancangan Sistem Kerja. Bandung, Jurusan TI ITB.

Gudi Tjahjono, (1996), Ancangan Sistematik dalam Pengembangan Sistem Transportasi Kota, seminar regional "strategi pengembangan Transportasi, Malang, Fakultas Teknik Univ. Widyagama.

Saufik Luthfianto, Siswiyanti, (2008) Pengujian Ergonomi Dalam Perancangan Desain Produk, Bandung, Prosiding Seminar Nasional Teknoin, hal. C.159-164.

Shirly Wunas, (2011), Kota Humanis, Integrasi Guna Lahan \& Transportasi di Wilayah Sub urban, Surabaya, Brilian Internasional.

Sritomo Wignjosoebroto, (2008), Ergonomi, Studi Gerak \& waktu. Jakarta, Guna widya.

Sudjana (1989), Metoda Statistika, Bandung. Tarsito. 